\title{
RELAÇÕES AMBIENTE/AGRICULTURA/ SUSTENTABILIDADE: DA DEGRADAÇÃO AMBIENTAL À NECESSIDADE DE CONSERVAÇÃO DOS RECURSOS NATURAIS ${ }^{1}$
}

Flórida Rosa Mali Assêncio* João Alberto da Silva Sé**

\section{Resumo:}

Este texto faz uma breve abordagem, destacando alguns aspectos históricos, sobre aspectos ambientais em relação ao desenvolvimento da agricultura no mundo e especialmente no Brasil. Com base em autores das Ciências Ambientais, de modo geral, e especificamente da Agroecologia, são apresentadas algumas características da degradação socioambiental decorrente de processos de produção convencional da agricultura, bem como a necessidade de se buscar novos modelos de desenvolvimento segundo o recente paradigma da sustentabilidade (social, econômica e ambiental), presente nos encontros e documentos internacionais sobre meio ambiente e desenvolvimento.

Palavras-chave: Agricultura,Agricultura Sustentável,Agroecologia, Meio Ambiente, Desenvolvimento Sustentável.

\section{A agricultura e o desmatamento}

Os ecossistemas florestais foram e continuam sendo ameaçados pela degradação descontrolada, devido à transformação para outros tipos de uso da terra. São vários os fatores que agravam essa situação, como a influência das crescentes necessidades humanas, da expansão agrícola, falta de controle adequado dos incêndios florestais,

'Este texto faz parte da dissertação (mestrado): "A visão dos proprietários rurais em relação às questões ambientais da microbacia do córrego da Roseira no município de Ibitinga-SP" (ASSÊNCIO, 2007).

*Bióloga e Mestre pelo Programa de Mestrado em Desenvolvimento Regional e Meio Ambiente do Centro Universitário de Araraquara - Uniara; docente da Faculdade Centro Paulista de Ibitinga (Facep).

***Doutor em Ciências da Engenharia Ambiental (PPG-SEA-EESC-USP); docente do curso de Ciências Biológicas e docente, orientador e pesquisador do Programa de Mestrado em Desenvolvimento Regional e Meio Ambiente do Centro Universitário de Araraquara - Uniara. 
exploração comercial não-sustentável da madeira, criação de gado excessiva e ausência de regulamentação para o plantio de pastagens, entre outros (AGENDA 21 BRASILEIRA, 2004).

No início do século XX, a área florestal mundial foi estimada em 5 bilhões de hectares, reduzindo-se desde então para 2,9 bilhões - aproximadamente o dobro da área cultivada, sendo este desmatamento causado pela demanda crescente por produtos florestais e a conversão acelerada de áreas florestais para a agricultura (BROWN, 2003).

Para Raven et al. (2003), deve-se reconhecer que o século XX foi um período único na história, pois apenas na segunda metade deste século a população mundial cresceu de 2,5 bilhões para mais de 6 bilhões, acarretando profundas consequiências ecológicas. Perdeu-se com a erosão cerca de um quarto da superfície das camadas externas dos solos da Terra e perto de um quinto da terra cultivável, em razão da combinação de práticas agrícolas inadequadas e abuso de áreas agrícolas marginais. Além de se alterar substancialmente a composição atmosférica, também se derrubou, sem reposição, cerca de um terço das florestas que existiam em 1950 (RAVEN et al., 2003).

O processo de ocupação do Brasil, segundo Martins (2001), foi um dos grandes agravantes dos problemas ambientais relacionados às florestas do país, uma vez que essa ocupação se caracterizou pela falta de planejamento e conseqüente destruição dos recursos naturais. Ao longo da história brasileira, a cobertura florestal nativa foi fragmentada, cedendo espaço para as culturas agrícolas, para as pastagens e para as cidades.

Nesse contexto, afirma Dean (1996) que a principal causa do desflorestamento no século XIX foi a queimada da floresta para plantar cafezais, porém o autor ressalta que não foi a única, já que o comércio do café motivou o crescimento demográfico, a urbanização, a industrialização e aimplantação de ferrovias, consequiências indiretas que exerceram pressões sobre uma área mais ampla da Mata Atlântica, dando início ao que agora pode ser considerado como danos irreversíveis a paisagens antropomorfizadas.

Para Rosa (1998), "...desde o início da exploração de pau-brasil, no período colonial, a relação do homem com essa floresta (Mata Atlântica) foi predatória e imediatista. Apesar de a região da Mata Atlântica ser hoje ocupada por grandes cidades, estradas e outras construções, o processo de sua destruição foi acontecendo, sobretudo pela expansão da fronteira agrícola, baseada na monocultura, primeiramente da cana-de-açúcar e depois do café. Em contrapartida, as áreas que se mantiveram a salvo do desmatamento possuem grandes declividades, que inviabilizam a ocupação agrícola ou urbana."

REVISTA UNIARA, $n .^{0} 21 / 22,2008 / 2009$
Segundo o Relatório do Brasil para a Conferência das Nações Unidas sobre Meio Ambiente e Desenvolvimento (BRASIL, 1991), a expansão da agricultura no país deveu-se ao avanço contínuo da fronteira agrícola e à introdução de técnicas de produção mais intensivas em capital. Como consequiência, as áreas dos estabelecimentos agrícolas praticamente dobraram entre 1950 e 1980. Reconhecese que os impactos de mais difícil recuperação dessa expansão horizontal foram as derrubadas e a eliminação da vegetação nativa, ocorridas em extensas áreas do território nacional.

O mencionado relatório revela ainda que, antes do surto cafeeiro, as florestas e outros ecossistemas nativos cobriam $82 \%$ da superfície territorial de São Paulo em 1973, esse número caiu para 8,3\%. No fim da década de 1940, quase $90 \%$ do território do norte do Paraná estava coberto por matas nativas; atualmente, essas matas cobrem pouco mais de $17 \%$ da região (Brasil, 1991). Impactos semelhantes a esses também foram detectados em outros estados.

Portanto, vários foram os fatores ligados à agricultura que contribuíram com os impactos ambientais hoje conhecidos, sendo muitas as transformações ocorridas na agricultura. Entre elas, destaca-se a Revolução Verde, implantada a partir dos anos 50, cujo pacote tecnológico básico foi estruturado a partir das sementes de Variedades de Alto Rendimento (VAR) e de um conjunto de práticas e insumos agrícolas necessários para assegurar as condições para que os novos cultivares alcançassem níveis crescentes de produtividade (CAPORAL, 2003).

Para Ehlers (1999), "...a euforia das 'grandes safras' propiciadas pelo padrão tecnológico da Revolução Verde logo cederia lugar a uma série de preocupações relacionadas tanto a seus impactos socioambientais quanto à sua viabilidade energética. Dentre as conseqüências ambientais da agricultura convencional se destacam: a erosão e a perda da fertilidade dos solos; a destruição florestal; a dilapidação do patrimônio genético e da biodiversidade; a contaminação dos solos, da água, dos animais silvestres, do homem do campo e dos alimentos".

A agricultura passou então a ser composta por novas relações sociais, tendo a agroindústria como setor dominante, ditando os processos produtivos desenvolvidos no meio rural, barrando a entrada e selecionando os produtores "mais capazes" de gerir esse novo negócio que é a agricultura moderna (CARRIERI; MONTEIRO, 1996). Observou-se então, segundo esses autores, a facilidade de o capital manipular as estruturas para organizar os indivíduos e os recursos, promovendo uma desterritorialização das pessoas de seus lugares e, em conseqüência, perdendo-se conhecimentos, saberes e práticas que outrora eram usados, por alguma razão, em determinados ambientes.

Ainda segundo Carrieri e Monteiro (1996), a introdução desse paradigma no 
Brasil permitiu ao Estado o desenvolvimento de ações que privilegiaram uma orientação para o desenvolvimento de sistemas de produção por produto, sendo gradativamente desconsiderados o ser humano, o meio ambiente e o contexto socioeconômico.

Diante desse quadro, típico da visão de mundo fragmentado em partes do paradigma cartesiano (as partes sendo mais importantes que o todo), em oposição à visão de mundo integrado do paradigma ecológico (o todo mais importante que as partes) (CAPRA, 2001), ações humanas com base nessas representações de meio ambiente (REIGOTA, 1997) geraram muitos impactos socioambientais importantes, relacionados diretamente às crescentes demandas por recursos naturais pela agricultura, pela industrialização, pelo crescimento demográfico, entre outros processos humanos contemporâneos, acarretando conseqüências que hoje são observadas em toda a biosfera.

Nesse sentido, Saraiva (1999) alerta que, entre os recursos naturais sujeitos a intensas pressões de uso, devem ser destacados a água e o solo como aqueles que, de um modo geral, suscitam maiores preocupações, dado que a sua utilização é essencial à maioria dos usos da sociedade e constitui fator limitante do desenvolvimento das comunidades vivas. Para o autor, a constatação desses fatos tem conduzido à procura de modelos integrados de planejamento e gestão que considerem os componentes ambientais na tomada de decisão aos vários níveis de intervenção, levando em conta as limitações impostas pela sua utilização racional e que minimizem os efeitos dessas decisões e atuações sobre os sistemas naturais.

Cabe ressaltar que, no Brasil, a preocupação com as conseqüências do desmatamento já ocorre há muitos anos. De acordo com Pádua (2004), no período entre 1862 e 1887, foram plantadas cerca de 95 mil mudas de árvores de diferentes espécies na Floresta da Tijuca, no Rio de Janeiro. Para o autor, o fator fundamental para tal reflorestamento foi garantir o abastecimento de água para a capital, sendo para isso recuperados os berços das nascentes dos principais rios utilizados pela população carioca à época.

Pádua (2004) salienta que "...talvez tenha tido razão o personagem de romance 'Sonhos d'ouro' de José de Alencar, publicado em 1872, ao classificar como 'viva imagem da loucura humana' o trabalho que a 'paciência e o inteligente esforço do major Archer' estava realizando no sentido de alinhar mudas de árvores de lei 'aos milhares pelas encostas'. Pois ele representava, de fato, uma tentativa de 'refazer à custa de anos de trabalho e dispêndio de grande cabedal, o que se destruiu em alguns dias pela cobiça de um lucro insignificante'. O mesmo 'homem civilizado', que 'abateu os troncos gigantes para fazer carvão', agora que precisava de 'sombra para obter água, arroja-se a inventar uma selva, como se fosse um palácio"'.

REVISTA UNIARA, $n . .^{0} 21 / 22,2008 / 2009$
Ainda segundo Pádua (2004), assim como em outros momentos da história humana, esse tipo de "loucura" acabou por deixar uma herança admirável para o futuro, pois embora a Floresta da Tijuca tenha sofrido um desinteresse público por parte das autoridades na década de 1880 (em decorrência do fato de o abastecimento de água vir de outras localidades), os plantios realizados na época foram suficientes para iniciar um processo irreversível de regeneração das matas. De acordo com o autor, o grande legado de todo esse esforço não foi a resolução do problema da água, mas sim a garantia de permanência da notável massa verde que ainda hoje caracteriza a paisagem do Rio de Janeiro.

\section{A agricultura sustentável}

A crítica aos modelos de desenvolvimento a partir da década de sessenta e os paradigmas emergentes, de acordo com Saraiva (1999), levaram à formulação de alternativas às questões decorrentes de um crescimento econômico sem limites, como a exploração dilapidadora de recursos e a acumulação excessiva de resíduos. Segundo o autor, questões como o estabelecimento de fronteiras ao crescimento econômico, de alternativas de desenvolvimento da sociedade, de preservação e gestão de recursos naturais, de necessidade de conservação da natureza e da biodiversidade têm sido amplamente analisadas e propondo então modelos, mais ou menos radicais, de alteração do processo de produção e de consumo das sociedades.

Para Ehlers (1999), em meados da década de 80, os impactos da agricultura moderna, a dilapidação das florestas tropicais, as chuvas ácidas, a destruição da camada atmosférica de ozônio, o aquecimento global e o "efeito estufa" tornaram-se temas familiares para grande parte da opinião pública, principalmente nos países ricos. Diante do exposto, houve um questionamento sobre até que ponto os recursos naturais suportariam o ritmo de crescimento econômico imprimido pelo industrialismo, ou mesmo se a própria humanidade resistiria às seqüelas do chamado "desenvolvimento".

Ainda segundo o autor, como respostas a essas dúvidas, consolidava-se um novo paradigma, um novo ideal - a sustentabilidade - quando, em 1987, a Comissão Mundial sobre Meio Ambiente e Desenvolvimento publicou "Nosso Futuro Comum", o famoso "Relatório Brundtland", contribuindo para a disseminação do ideal de um desenvolvimento sustentável para diferentes setores das sociedades modernas, como a agricultura e a economia. Reafirmando esse ideal, ocorreu também a Conferência das Nações Unidas sobre Meio Ambiente e Desenvolvimento, a Rio-92.

Quirino et al (1999) complementam, afirmando que essa conscientização ambiental foi motivada em grande parte pela divulgação do relatório e das conferências anteriormente citados, bem como pelos desdobramentos da Rio-92, como a Rio+5 
no Rio de Janeiro, a Convenção da Biodiversidade em Genebra, Suíça, e a de Mudanças Climáticas Globais em Kyoto, Japão.

Nesse contexto, de acordo com Saraiva (1999), "...o conceito de desenvolvimento sustentável é atualmente apontado como referência de modelos de desenvolvimento e paradigma de uma relação mais simbiótica entre desenvolvimento e equilíbrio ambiental. As suas implicações e incidências são examinadas relativamente aos temas considerados, constatando-se, no entanto, grandes lacunas quanto ao seu conteúdo e formas de aplicação nos vários domínios de intervenção que incidem sobre o ordenamento e gestão dos recursos naturais".

Para Martins (1999), "...o conjunto de princípios que balizam o desenvolvimento sustentável exige a harmonia entre as dimensões econômica, social e ambiental como um todo indivisível. Ou seja, as dimensões não podem ser tratadas individualmente. Esta é uma das grandes tendências para o próximo século: não há como pensar em desenvolvimento sem resolver o desafio da sustentabilidade, que representa um poderoso instrumento para fortalecer a consciência da dignidade humana e sua relação com um planeta habitável para nós e nossos descendentes. As novas demandas exigem produtos mais sadios, sistemas de produção que não comprometam a natureza e a saúde de trabalhadores e consumidores. Necessitamos de uma atmosfera mais limpa e uma melhor qualidade de vida, tanto no meio rural como no urbano".

Ehlers (1999) diz que "...a palavra 'sustentável', originária do latim sus-tenere, é usada em inglês desde 1290 e as referências ao termo sustentável em relação ao uso da terra, dos recursos bióticos, florestais e dos recursos pesqueiros também são anteriores à década de 80 . Mas é a partir de meados dos anos 80 que a expressão agricultura sustentável passa a ser empregada com maior frequiência, assumindo também dimensões econômicas e socioambientais. Desde então, multiplicaram-se as definições e as explicações sobre a agricultura sustentável, sobre suas práticas e seus objetivos".

Ainda de acordo com o autor, foi a partir dessa década que as evidências da degradação ambiental e a ineficiência energética dos sistemas produtivos motivaram um grande número de pesquisadores e produtores a repensar os fundamentos da agricultura moderna, mesmo porque crescia a pressão da opinião pública sobre os órgãos governamentais responsáveis pela salubridade dos alimentos e pela defesa do meio ambiente. Nesse sentido, o autor afirma que foi fundamental a participação de entidades protetoras dos direitos dos consumidores e de entidades ambientalistas, as organizações não-governamentais (ONGs), que se colocaram, junto com o setor público e com o setor privado, como um terceiro agente nos processos de decisão.

Portanto, nesse sentido de articulação, Ehlers (1999) comenta que a década de 80 representou para a agricultura norte-americana um período de profundas

REVISTA UNIARA, $n .^{0} 21 / 22,2008 / 2009$ mudanças, sendo que novos grupos e diferentes idéias passaram a influenciar as políticas agrícolas, fazendo com que muitos agricultores, pesquisadores e até instituições inteiras começassem a reexaminar e a repensar as práticas, os objetivos e as consequiências de modelo convencional. Com isso, reconheceu-se a necessidade de conciliar a produção, a conservação ambiental e a viabilidade econômica da agricultura.

Segundo Veiga (2003), vários são os conceitos de "agricultura sustentável", porém todas transmitem a visão de um futuro padrão produtivo de alimentos, fibras e matérias-primas energéticas que garanta:

- a manutenção, no longo prazo, dos recursos naturais e da produtividade agropecuária;

- o mínimo de impactos adversos ao ambiente;

- retornos adequados aos produtores;

- otimização da produção com um mínimo de insumos externos;

- satisfação das necessidades humanas de alimentos e renda;

- atendimentos às demandas sociais das famílias e comunidades rurais.

Verifica-se assim que "...os defensores da chamada agricultura sustentável alegam que esta proposta tem como objetivo resgatar os sistemas de produção diversificados e condizentes com a vocação da terra, propondo uma sustentabilidade ecológica e econômica dos sistemas de produção agrícolas, tendo como base a conservação dos recursos renováveis, a adaptação da agricultura ao ambiente e a manutenção de um nível alto, porém sustentável, de produtividade. Essa proposta teria como fundamento o respeito às formas gerenciais existentes dos produtores (principalmente dos pequenos e familiares), considerados atores conscientes que selecionam seus próprios critérios de ação de acordo com as especificidades de seu meio, e constroem seus próprios modelos específicos de produção" (CARRIERI; MONTEIRO; 1996).

Segundo Rosa (1998), as propostas de agricultura sustentável procuram respeitar os processos naturais, trabalhando junto com eles, e não contra eles, como é feito na agricultura convencional, buscando minimizar as perturbações dos ciclos naturais, evitando práticas que resultem em excessiva artificialização e simplificação do ambiente. Assim sendo, os campos agrícolas deveriam ser considerados ecossistemas especiais, denominando-se agroecossistemas, onde o conhecimento da ecologia seria aplicado à agricultura (ROSA, 1998).

Nesse ambiente de busca e construção de novos conhecimentos nasceu a Agroecologia, como um novo enfoque científico capaz de dar suporte a uma transição para estilos de agriculturas sustentáveis e, portanto, contribuir para o estabelecimento de processos de desenvolvimento rural sustentável; sendo que, a partir dos princípios ensinados pela Agroecologia, passaria a ser estabelecido um novo caminho para a 
construção de agriculturas de base ecológica ou sustentável (CAPORAL; COSTABEBER; 2004).

Esses mesmos autores dizem que, a Agroecologia se consolida nutrindo-se do conhecimento de outras disciplinas científicas, bem como de saberes, conhecimentos e experiências dos próprios agricultores, permitindo com isso o estabelecimento de marcos conceituais, metodológicos e estratégicos com maior capacidade para orientar não apenas o desenho e manejo de agroecossistemas sustentáveis, mas também processos de desenvolvimento rural sustentável. Isso é buscado, ainda segundo eles, nos conhecimentos e experiências já acumulados, ou através da investigação-ação participativa ou do diagnóstico rural participativo, por exemplo, um método de intervenção que, ademais de manter coerência com suas bases epistemológicas, contribua na promoção das transformações sociais necessárias para gerar padrões de produção e consumo mais sustentáveis.

Stephen Gliessman (2000), professor e pesquisador da Universidade da Califórnia, que há 25 anos trabalha nessa área, em entrevista cedida à jornalista Ângela Filippe da EMATER/RS, diz que Agroecologia se oferece como alternativa aos problemas que observamos na agricultura moderna, que necessitamos voltar a incorporar dentro dos agroecossistemas todo um conhecimento ecológico de desenho, de manejo, que mantenha dentro dos agroecossistemas toda a complexidade de interações de componentes necessários para sustentar esses sistemas através do tempo e, ao mesmo tempo, siga produzindo o que necessitamos. O autor diz que a agricultura moderna, num certo grau, perdeu sua base ecológica e a Agroecologia está nos oferecendo uma forma de reintroduzir essas bases.

Gliessman (2000) ressalta ainda que a agricultura convencional, dita moderna, mostra indícios de sua falta de sustentabilidade quando se conferem os indicadores como: o custo excessivo dos insumos, o impacto negativo que tem sobre o meio ambiente, o baixo ingresso econômico que produz e também todo o impacto que tem havido sobre o setor agrícola sob o aspecto do campo.

No entanto, ele afirma que é possível tornar a agricultura sustentável por meio da Agroecologia, pois assim como a natureza sempre está se renovando, renovando sua capacidade produtiva, pode-se fazer o mesmo com os agroecossitemas.

Para Caporal e Costabeber (2004), "...cabe reconhecer os enormes desafios que estão pela frente se o objetivo é fazer avançar o enfoque agroecológico, numa perspectiva de agriculturas e desenvolvimento rural sustentáveis. Tais desafios são muito grandes e complexos, mas não são, em absoluto, intransponíveis. Sua superação depende, primeira e principalmente, da capacidade de diálogo e de aprendizagem coletiva que se possam estabelecer entre diferentes setores da sociedade, assim como do reconhecimento de que a sustentabilidade encerra não apenas abstrações

REVISTA UNIARA, $n .^{0} 21 / 22,2008 / 2009$ teóricas e perspectivas futuristas, mas também elementos práticos que devem ser adotados na vida cotidiana".

Ainda de acordo com os autores, "...a socialização de conhecimentos e saberes agroecológicos entre agricultores, pesquisadores, estudantes, extensionistas, professores, políticos e técnicos em geral - respeitadas as especificidades de suas áreas de atuação - é, e seguirá sendo, uma tarefa imperativa neste início de milênio, o que determina a necessidade de participação ativa do Estado. Se isso é verdadeiro, cabe também a todos os cidadãos o dever - e também o direito - de trabalharmos pela ampliação das oportunidades de construção de saberes socioambientais, necessários para consolidar um novo paradigma de desenvolvimento rural, que considere as seis dimensões (ecológica, social, econômica, cultural, política e ética) da sustentabilidade. Como enfoque científico e estratégico de caráter multidisciplinar, a Agroecologia apresenta a potencialidade para fazer florescer novos estilos de agricultura e processos de desenvolvimento rural sustentáveis que garantam a máxima preservação ambiental, respeitando princípios éticos de solidariedade sincrônica e diacrônica".

Muito se falou até aqui de agricultura sustentável, da Agroecologia como modelo para isso, de suas vantagens em relação à agricultura convencional e dos fatores importantes para a sua implantação. No entanto, para que os caminhos rumo a ela surjam fortes, Assêncio (2007) acredita ser extremamente necessária a participação dos proprietários rurais, pois são protagonistas importantes para que a mesma não seja apenas uma utopia no atual contexto rural. No entanto, prossegue a autora, esses proprietários, especialmente os pequenos proprietários, necessitam de encorajamento com políticas que venham a estimulá-los, com apoio, respeito e acima de tudo dignidade. O trabalho de Assêncio (2007) foi realizado com o objetivo de ouvi-los e possibilitar a criação de um canal de diálogo entre a realidade e a teoria, para que, em conjunto, possam oferecer sua contribuição a um caminho para a sustentabilidade socioeconômica-ambiental.

Nesse sentido, de acordo com Elicher (2002), a necessidade de conciliar a produção, a conservação ambiental e a viabilidade econômica da agricultura não está garantida pelo simples fato de se adotar uma alternativa produtiva, já que esse processo não se resume à adoção ou ao retorno do uso de técnicas e práticas diferenciadas, poupadoras de recursos energéticos e do equilíbrio dos ecossistemas. Trata-se, sobretudo, de construir no mundo vontade política para mudar essas questões, que procure proporcionar a melhor distribuição das riquezas, o investimento em tecnologias e, principalmente, saber se essa opção será suficiente para manter o pequeno produtor no campo e se conseguirá sustentar a demanda de produção de alimentos numa esfera global.

Relações ambiente/agricultura/sustentabilidade... 


\section{Referências bibliográficas:}

AGENDA 21 BRASILEIRA. Resultado da Consulta Nacional/Comissão de Políticas de Desenvolvimento Sustentávele da Agenda 21 Nacional. 2. ed. Brasília: Ministério do Meio Ambiente, 2004.

ASSÊNCIO, F.R.M. A visão dos proprietários rurais em relação às questões ambientais da microbacia do córrego da Roseira no município de Ibitinga-SP. 2007.193f.. Dissertação (mestrado). Programa de Pós-Graduação em Desenvolvimento Regional e Meio Ambiente - Centro Universitário de Araraquara - UNIARA. Araraquara-SP.

BRASIL. Comissão Interministerial para preparação da Conferência das Nações Unidas sobre Meio Ambiente e Desenvolvimento - CIMA. O desafio do desenvolvimento sustentável: relatório do Brasil para a Conferência das Nações Unidas sobre Meio Ambiente e Desenvolvimento. Brasília: CIMA, 1991.

BROWN, L.R. Eco-Economia: construindo uma economia para Terra. Salvador: UMA, 2003.368p.

CAPORAL, F.R. Superando a Revolução Verde: a transição agroecológica no estado do Rio do Rio Grande do Sul. 2003. Disponível em:

<www.agirazul.com.br/artigos/caporall.htm>.Acesso em: 14 jun. de 2006.

CAPORAL, F.R.; COSTABEBER, J. A. Agroecologia: conceitos e princípios para a construção de estilos de agriculturas sustentáveis. 2004. Disponível em: <www.planetaorganico.com.br/trabCaporalCostabeber.htm>. Acesso em: 20 jul. 2006.

CAPRA, F. A teia da vida. 6. ed. São Paulo: Pensamento-Cultrix, 2001.

CARRIERI, A.P.; MONTEIRO, A.V.V.M. A agricultura sustentável e a biotecnologia: trajetórias tecnológicas e a (neo) territorialização no campo.

Informações Econômicas, São Paulo, v.26, n.4, abr. 1996.

DEAN, W. A ferro e fogo: a história e a devastação da Mata Atlântica brasileira. São Paulo: Companhia das Letras, 1996.

REVISTA UNIARA, $n .^{0} 21 / 22,2008 / 2009$
EHLERS, E. Agricultura sustentável: origens e perspectivas de um novo paradigma. Porto Alegre: Ed. Guaíba: Agropecuária, 1999.

ELICHER, M.J. A Agroecologia como crítica ao modelo da "Revolução Verde". 2002. Disponível em: <www.igeo.uerj.br/VICBG-2004/Eixo3/ E3_032.htm>.Acesso em: 15 jul. 2006.

GLIESSMAN, S. A agricultura pode ser sustentável. Entrevista concedida a Ângela Filippi. Agroecologia e desenvolvimento rural sustentável, EMATER/ RS, n.3, jun. 2000. Disponívelem: <www.emater.tche.br/docs/agroeco/revista/n3/ index.htm>. Acesso em: 20 jul. 2006

MARTINS, S.V. Recuperação de matas ciliares. Viçosa: Aprenda Fácil, 2001.

MARTINS, S.R. Estratégia para a construção do ideário da sustentabilidade agrícola. Texto referente à palestra proferida pelo autor. In: SEMINARIO MANEJO DA VEGETAÇÃO SECUNDÁRIAPARAA SUSTENTABILIDADE DAAGRICULTURAFAMILIAR DAAMAZONIA ORIENTAL. Anais... Belém, CPATU/EMBRAPA, 2001. Disponível em: <www.emater.tche.br/docs/agroeco/revista/n2/13-artigo3.htm> Acesso em: 10 nov. 2006.

PÁDUA, J.A. Um sopro de destruição: pensamento político e crítica ambiental no Brasil escravista (1786-1888). 2. ed. Rio de Janeiro: Jorge Zahar, 2004.

QUIRINO, T.R.; IRIAS, L.J.M.; WRIGHT, J.T.C. Impacto agroambiental perspectivas, problemas e prioridades. São Paulo: Edgard Blücher, 1999.

RAVEN, H.P.; EVERT, F.R.; EICHRORN, S.E. Biologia vegetal. 6. ed. Rio de Janeiro: Guanabara Koogan, 2003.

REIGOTA, M. Meio ambiente e representação social. 2. ed. São Paulo: Cortez, 1997. 87p.

ROSA, A.V. Agricultura e meio ambiente. São Paulo: Atual, 1998.

SARAIVA, M.G.M.A.N.L. O rio como paisagem - gestão de corredores

Relações ambiente/agricultura/sustentabilidade... 
fluviais no quadro do ordenamento do território. São Paulo: Fundação Calouste Gulbenkian/Fundação para Ciência e Tecnologia, 1999.

VEIGA, J.E. A agricultura no mundo moderno: diagnóstico e perspectiva. In: TRIGUEIRO, A. (Coord.). Meio ambiente no século 21: 21 especialistas falam da questão ambiental nas suas áreas de conhecimento. Rio de Janeiro: Sextante, 2003. p.199-213.

Title:

ENVIRONMENT, AGRICULTURE AND SUSTAINABILITY

RELATIONS: FROM THE ENVIRONMENTAL DEGRADATION TO THE NECESSITY OF CONSERVATION OF NATURAL RESOURCES.

\section{Abstract:}

This paper presents a brief approach on environmental aspects related to the development of agriculture in the world and especially in Brazil, detaching some historical aspects. Some characteristics of the social and environmental degradation generated by the processes of production of modern agriculture, based on studies of Environmental Sciences, in general, and, more specifically, of Agroecology, are presented, as well as the necessity of searching for new models of development according to the recent paradigm of sustainability (social, economic and environmental), debated in international conferences on 'environment and development'.

Keywords: Agriculture, Sustainable Agriculture, Agroecology, Environment, Sustainable Development. 